\title{
Sand-geotextile interface characterization through monotonic and cyclic direct shear tests
}

\author{
Castorina Silva Vieira ${ }^{1}$, Maria de Lurdes Lopes ${ }^{2}$, Laura M. Caldeira ${ }^{3}$ \\ ${ }^{1}$ Assistant Professor, Faculty of Engineering, University of Porto, R. Dr. Roberto Frias, 4200-465 Porto, \\ Portugal, Telephone: +351 225081586, Telefax: +351 225081446, E-mail: cvieira@fe.up.pt \\ ${ }^{2}$ Professor, Faculty of Engineering, University of Porto, R. Dr. Roberto Frias, 4200-465 Porto, Portugal, \\ Telephone: +351 225081564, Telefax: +351 225081446, E-mail: lcosta@fe.up.pt \\ ${ }^{3}$ Principal Research Officer, National Laboratory of Civil Engineering, Av. do Brasil 101, 1700-066 \\ Lisbon, Portugal, Telephone: +351 218443335, Telefax: +351 218443021, E-mail: laurac@lnec.pt
}

\begin{abstract}
For the design and performance analyses of geosynthetic-reinforced soil structures under repeated loadings, such as those induced by compaction, traffic and earthquakes, the understanding of cyclic soil-geosynthetic interface behaviour is of great interest. Nevertheless, the experimental data concerning this type of behaviour are very scarce. To complement this lack of knowledge, a laboratory study was carried out and described in this paper. This paper presents the behaviour of an interface between a silica sand and a high strength geotextile under monotonic and cyclic loading conditions. A large scale direct shear test device able to perform load or displacement controlled cyclic tests was used. The results obtained are presented and discussed, specially in terms of interface shear stiffness and damping ratio. Monotonic direct shear tests pointed out that the coefficients of interaction for the sand/geotextile interface depend on the confining pressure. Cyclic direct shear tests indicated that the interface stiffness tends to increase during the first loading cycles suffering slight variations after 10 cycles. Slightly higher values of shear stiffness and damping ratio were reached with displacement controlled cyclic direct shear tests. The cyclic loading of the interface did not lead to the degradation of the post-cyclic peak shear strength however the postcyclic shear strength for large displacements experienced an important decrease.
\end{abstract}

KEYWORDS: Direct shear tests, Cyclic direct shear tests, Shear strength, Damping, Interface shear stiffness 


\section{INTRODUCTION}

Soil-reinforcement interaction mechanism has an utmost importance in the design of reinforced soil structures. This mechanism depends on the soil properties, reinforcement characteristics and elements (soil and reinforcement) interaction. The accurate identification of the interaction mechanism and the choice of the most suitable test for its characterization are important factors. Figure 1 presents a potential failure mechanism of a reinforced soil slope. In upper part of the retained reinforced soil mass, the reinforcement is pulled out so the soil-reinforcement interaction can be best characterised by laboratory by pullout tests. Near the base of the slope, soil sliding is expected and the interaction between the two materials is better characterised trough direct shear tests.

Over the last decades, many researchers have been investigated static shear properties of soil-geosynthetic interfaces (Palmeira 1987; Bemben and Schulze 1998; Nakamura et al. 1999; Lee and Manjunath 2000; Silvano and Lopes 2005; Vieira 2008; Liu et al. 2009a; Anubhav and Basudhar 2010; Khoury et al. 2011). In contrast, the behaviour of those interfaces under cyclic loading has not been so broadly studied.

Experimental studies have been conducted on a variety of geosynthetic interfaces. Yegian and Lahlaf (1992) carried out shaking-table tests to measure the dynamic interface shear strength properties between geotextiles and geomembranes. Yegian and Kadakal (1998) presented an overview of geosynthetic interfaces behaviour under dynamic loading, including typical test results and a description of a constitutive model for geosynthetic-geosynthetic interfaces. De (1996) performed a series of tilt table tests and cyclic direct shear tests to characterize the interfacial friction properties of some geosynthetic interfaces commonly included in landfill liner systems. De and Zimmie (1998) presented laboratory test results on different interfaces, formed through various combinations of three geosynthetics (a geotextile, a smooth geomembrane, and a geonet). The dynamic properties of these interfaces were estimated using a cyclic direct shear device, a shaking table device and a shaking table device on a geotechnical centrifuge. Kim et al. (2005) conducted an experimental study on a shaking table, to investigate the relationship between dynamic friction strengths and shear displacement rate of geosynthetic interfaces. Nye and Fox (2007) presented results from monotonic and cyclic displacement-controlled direct shear tests to characterize the internal shear 
behaviour of a hydrated needle-punched geosynthetic clay liner. Fox et al. (2011) reported an experimental program with regard to cyclic loading of geomembrane/coarse sand interfaces.

A few researches related to the soil-geosynthetic interface interaction under pullout cyclic load conditions are available in literature (Yasuda et al. 1992; Fannin and Raju 1993; Min et al. 1995; Mayer et al. 2004; Moraci and Cardile 2009).

Reports of cyclic direct shear tests on soil/geosynthetics interfaces are scarce. O'Rourke et al. (1990) carried out 20 repeated direct shear tests on a single sample of HDPE sheet with Ottawa sand at low confining pressure $(20.7 \mathrm{kPa})$. Yegian et al. (1995) conducted an experimental investigation, using shaking table tests, of the dynamic shear strength properties of a geomembrane/soil (Ottawa sand) interface. Recently, Ling et al. (2008) performed a series of direct shear tests to investigate the strength of soil/geogrid and soil/concrete interfaces under monotonic and cyclic loading. These authors used a modified direct shear device, with dimensions in plan of $100 \mathrm{~mm} \times 100 \mathrm{~mm}$. The cyclic tests were performed with a constant displacement rate of $2 \mathrm{~mm} / \mathrm{s}$ and 15 cycles were applied to the interface when the shear stress reached $56-74 \%$ of its monotonic shear strength.

As previously referred, most of the studies related to the dynamic characterization of interfaces were carried out in shaking tables. In these devices, a geosynthetic specimen is placed on the table surface and another geosynthetic specimen is attached to the bottom of a rigid block or, if a geosynthetic/soil interface is tested, a box filled with soil is placed upon the table. The shaking table is excited and, when the interface strength is exceeded, a relative displacement between the box and the table occurs. Then from the imposed acceleration at the moment when the box starts to move, a dynamic interface strength can be estimated. Nevertheless, these devices do not allow controlling the relative displacements on the interfaces.

There is another type of shaking table setup, where the block is fixed to reaction frames located outside of the shaking table. Once the shaking table is excited, the strength on the interface is transferred from the table to the block above and is measured by means of load cells mounted between the block and reaction frames (Kim et al. 2005). This setup is able to control the relative displacement between the block and the table however it is more difficult to set up than the more common shaking table devices. 
The understanding of cyclic soil-geosynthetic interfaces behaviour is crucial for the design and performance analyses of geosynthetic-reinforced soil structures under repeated loadings. In the seismic design of geosynthetic reinforced soil structures, it is common to use the interface shear strength evaluated under monotonic loading (or estimated as a ratio of soil friction angle) to analyse the sliding stability along the geosynthetic interface with the reinforced fill or the foundation. FHWA (2010) suggests the use of the interface friction coefficient, determined from soil-geosynthetic direct shear tests in accordance with the ASTM D 5321 (2002), in sliding stability analyses of geosynthetic reinforced soil retaining walls either in static or seismic conditions.

Notwithstanding there are few previous laboratory studies showing that under dynamic loading no reduction in soil-geosynthetic interface shear strength occurs.

The numerical simulations of reinforced soil structures offer the possibility to study the influence of several parameters on the structure behaviour and particularly, the effects of dynamic loading on its performance. However, reliable numerical analyses require proper modelling of soil-geosynthetic interfaces. Experimental data are essential for the development and calibration of constitutive relations. With the results of monotonic and cyclic direct shear tests presented in this paper is intended to increase the available experimental data that could be used in the development of proper constitutive models.

The conventional direct shear device can only accommodate small size specimens, which imposes serious limitations in terms of reproducing real conditions. Based on this evidence, a large scale direct shear test device able to perform load and displacement controlled cyclic tests was designed and will be presented in sequence.

\section{LABORATORY PROTOTYPE}

\subsection{General aspects}

When sliding of the soil mass along the geosynthetic is expected (Figure 1), the most suitable laboratory test to characterise the interaction between the two materials is the direct shear test.

In the scope of research on soil-geosynthetic interface characterization (Vieira 2008), a laboratory prototype of a large scale direct shear test device, able to perform 
monotonic and cyclic direct shear tests, was designed and built at University of Porto. The development of this prototype was based on the European (EN ISO 12957-1, 2005) and North American (ASTM D 5321, 2002) standards. To increase the versatility of the equipment, the device was designed to perform load or displacement controlled cyclic tests.

\subsection{Description of the apparatus}

The developed large scale direct shear device is based on a hydraulic actuation with closed loop command computer control. The equipment consists of the shear box, a support structure, five hydraulic actuators and respective fluid power unit, an electrical cabinet, internal and external transducers and a computer. Figure 2 presents an overall view of the equipment.

The shear box comprises an upper box, fixed in the horizontal directions, with dimensions of $300 \mathrm{~mm} \times 600 \mathrm{~mm}$ in plant and $150 \mathrm{~mm}$ in height, and a lower box, with dimensions of $340 \mathrm{~mm} \times 800 \mathrm{~mm}$ in plan and $100 \mathrm{~mm}$ in height, rigidly fixed to a mobile platform running on low friction linear guides.

The vertical position of the upper box is controlled by two hydraulic actuators positioned in its short edges (Figure 2). A rigid base or a rigid ring can be inserted in the lower box. When the rigid base is placed inside the lower box, the apparatus is able to perform direct constant contact area shear tests. If the rigid ring is put in place, a reduced contact area shear box (with $300 \mathrm{~mm}$ x $600 \mathrm{~mm}$ ) is materialized.

For characterization of soil-geosynthetic or geosynthetic-geosynthetic interfaces, the standards EN ISO 12957-1 (2005) and ASTM D 5321 (2002) define minimum dimensions of $300 \mathrm{~mm}$ by $300 \mathrm{~mm}$. The shear box was built with a larger length to test uniaxial geogrids with large openings, in order to comply with EN ISO 12957-1 (2005). According to this standard, the minimum dimensions of the shear box for testing geogrids shall be such that at least two full longitudinal ribs and three transverse bars are contained within the length of both upper and lower boxes.

The influence of the shear box dimensions on the direct shear test results is not consensual. Some authors (Ingold 1982; Imaizumi et al. 1994) concluded that the interface shear strength decreases when shear boxes dimensions increase and other authors (Hsieh and Hsieh 2003) referred that the friction angles obtained with direct 
shear boxes with larger dimensions are greater than those determined with smaller shear boxes. Palmeira $(1987,1988)$ stated that scale does not affect the values of the peak friction or dilatation angles measured at the top boundary, but the post peak behaviour are scale dependent.

Usually the main differences among test arrangements are related to the way how the geosynthetic is fixed and the normal stress is applied to the soil sample (Palmeira 2009). The geosynthetic specimens are connected to the lower box, outside of the shear area, by rigid bars with several screws located at each edge of the box. Although the European Standard (EN ISO 12957-1, 2005) states that the geosynthetic should be clamped at the front part of the box, in the developed device this gripping system was not suitable to the cyclic direct shear tests.

The normal stress is applied to the soil by a rigid plate, as used by several authors (Bakeer et al. 1998; Lee and Manjunath 2000; Liu et al. 2009a), through a servoactuation solution composed by two pressure controlled double acting linear actuators, and can reach values up to $200 \mathrm{kPa}$. The measurement of the applied force is accomplished indirectly by a pressure transducer, with accuracy of $\pm 1 \%$.

The horizontal movement of the lower box is induced by a hydraulic servoactuator (Figure 2), allowing a maximum compression of $50 \mathrm{kN}$ and a maximum traction of $33 \mathrm{kN}$ (at a maximum hydraulic pressure of $16 \mathrm{MPa}$ ). The shear force is measured by a tension/compression load cell. There is a magnetostrictive displacement transducer of $200 \mathrm{~mm}$ inside the hydraulic servoactuator to measure the horizontal displacement of the lower box. The equipment has also four external inductive displacement transducers $(L V D T)$ to record horizontal and vertical movements.

Cyclic actions can be applied in horizontal and vertical directions. In shear direction, the equipment is able to perform displacement or load controlled tests. A compromise between the amplitude and the frequency of the cyclic loading must be observed due to power limitations. For instance, displacement controlled tests can be performed with frequencies up to $5 \mathrm{~Hz}$ if the cycle displacement amplitude is less than $\pm 2 \mathrm{~mm}$. For lower frequencies, this amplitude can reach up to $\pm 100 \mathrm{~mm}$. In vertical direction, the cycles are load controlled. The amplitude of the normal stress cycles can reach values up to $\pm 45 \mathrm{kPa}$ and a maximum frequency of $2 \mathrm{~Hz}$. 


\subsection{Performance of the developed device in monotonic conditions}

When a prototype is developed, a performance evaluation, through the examination of the different potentialities and the results calibration, is essential. For this purpose, the apparatus was subject to an extensive program of testing and calibration (Silvano 2005; Vieira 2008).

To appraise the reproducibility of the results, Figure 3 presents the curves of shear stress as a function of relative shear displacement for several tests, performed under the same conditions, to characterize the interface between a high strength geotextile and a poorly graded sand (see section 3). The normal stress was kept constant during the tests and equal to $50 \mathrm{kPa}$. Table 1 presents a summary of these reproducibility tests, displaying the values of the maximum shear stress, $\tau_{\max }$, the shear displacement for $\tau_{\max }$, $\Delta_{\mathrm{hx}}$, and the shear stress for a $40 \mathrm{~mm}$ relative displacement, $\tau_{40 \mathrm{~mm}}$ obtained in the five tests. The mean values, the standard deviation and the coefficient of variation are also presented.

The difficulties associated to direct shear tests under lower confining pressures are well known. Nevertheless, the coefficients of variation of the peak shear strength, $\tau_{\max }$, and of the corresponding shear displacement, $\Delta_{\mathrm{hx}}$, were lower than $5 \%$. The variation of the large displacement shear strength was slightly higher even so, it was considered acceptable.

For the same value of the normal stress $(50 \mathrm{kPa})$, the coefficients of variation of the peak shear strength, related to a sand/geotextile interface, reported by Stoewahse et al. (2002) were $7 \%$ and $28 \%$ for direct shear tests carried out under conditions of repeatability at Hanover University and Loughborough University, respectively. For lower normal stresses and for tests performed in different laboratories, coefficients of variation greater than $25 \%$ were reported.

For the validation of the equipment other reproducibility tests were carried out. Interface direct shear strengths obtained with the developed device were also compared with results achieved in small $(60 \mathrm{~mm} \times 60 \mathrm{~mm})$ conventional direct shear apparatus (Vieira 2008). 


\section{MATERIALS AND TEST PROCEDURES}

In the laboratory study herein presented, the interface between a silica sand and a high strength geotextile (geocomposite reinforcement) was characterized. According to the Unified Soil Classification System, the sand is classified as $S P$ - poorly graded sand and it was referred as SP49. This sand has mean diameter of $0.45 \mathrm{~mm}$, uniformity coefficient of 1.9 and coefficient of curvature equal to 0.9 .

The geocomposite is a high strength composite geotextile, consisting of polypropylene continuous filament needlepunched nonwoven and high strength polyester yarns (unidirectional reinforcement), with a nominal strength of $50 \mathrm{kN} / \mathrm{m}$ and elongation at nominal strength of $13 \%$. This geocomposite was designated as GC50.

The direct shear tests were performed with the rigid base placed on the lower box (constant contact area tests). To prevent relative displacements between the specimen and the rigid support, an aluminium oxide abrasive sheet ( $P 80$ type) was glued to the rigid support and the geosynthetic specimen was gripped with screws at the four edges of the lower box.

The sand was placed inside the upper shear box, at its air-dried water content, with relative density $\left(I_{D}\right)$ of $70 \%$ or $90 \%$. The sand was compacted in two $25 \mathrm{~mm}$ thick layers to the target unit weight.

The monotonic direct shear tests were conducted with a constant displacement rate of $1 \mathrm{~mm} / \mathrm{min}$ at normal stresses of 50,100 and $150 \mathrm{kPa}$. The cyclic direct shear tests were performed with a normal stress of $100 \mathrm{kPa}$. Prior to shearing, the normal stress was applied to the specimens for one hour. After this period, the settlement of the soil under the pre-established normal stress was stabilised in all specimens.

\section{RESULTS OF MONOTONIC DIRECT SHEAR TESTS}

The evolution of the shear stress and the vertical displacement of the rigid plate centre as function of the shear displacement along direct shear tests on sand SP49/geocomposite GC50 interface is shown in Figure 4. In these direct shear tests the sand was placed inside the upper shear box with a relative density of $70 \%$.

The shear stress-shear displacement curves, plotted in Figure 4a, show a well-defined peak shear strength, which was recorded for shear displacements that increased with the confining pressure. As expected, initially, the sand exhibited a contraction followed by a 
dilating phase (Figure $4 \mathrm{~b}$ ). For the intermediate vertical stress $(100 \mathrm{kPa})$, the shear stress behaviour was consistent with the tests carried out at the lower and higher vertical stresses. However, its vertical displacement evolution presented a contractile behaviour, similar to the one observed at the higher stress $(150 \mathrm{kPa})$, and a dilation at the end of test larger than the one observed in the other tests.

Figure 5 presents the peak and the large displacement shear strengths for the three values of the confining pressure $(50 \mathrm{kPa} ; 100 \mathrm{kPa}, 150 \mathrm{kPa})$, as well as, the corresponding linear best fit. Following Coulomb failure criterion, the SP49/GC50 interface presented an apparent adhesion $c_{a, p}=7.5 \mathrm{kPa}$ and a peak friction angle $\delta_{p}=31.4^{\circ}$. The large displacement strength can be defined by an apparent adhesion $c_{a, c v}=7.1 \mathrm{kPa}$ and friction angle $\delta_{\mathrm{cv}}=27.6^{\circ}$. The failure envelopes show an apparent adhesion for the sand/geotextile interface due to the nonlinearity of the relationship between the shear strength and the normal stress at lower confining stresses. The apparent adhesion has been also reported by other authors for sand/geosynthetic interfaces (Cazzuffi et al. 1993; Ling et al. 2002; Chenggang 2004, Liu et al. 2009b).

The coefficient of interaction or friction ratio (EN ISO 12957-1, 2005), $\mathrm{f}_{\mathrm{g}}$, is defined as the ratio of the maximum shear stress in a soil/geosynthetic direct shear test, $\tau_{\text {soil/geo }}^{\max }(\sigma)$, to the maximum shear stress in a direct shear test on soil, $\tau_{\text {soil }}^{\max }(\sigma)$, under the same normal stress $\sigma$ :

$$
\mathrm{f}_{\mathrm{g}}=\frac{\tau_{\text {soil } / \mathrm{geo}}^{\max }(\sigma)}{\tau_{\text {soil }}^{\max }(\sigma)}=\frac{\mathrm{c}_{\mathrm{a}}+\sigma \tan \delta}{\mathrm{c}+\sigma \tan \phi}
$$

For cohesionless soils and if no apparent adhesion is stated, the coefficient of interaction can be reduced to:

$$
\mathrm{f}_{\mathrm{g}}=\frac{\tan \delta_{\mathrm{p}}}{\tan \phi}
$$

being only function of soils and geosynthetics characteristics and independent of the normal confining pressure.

Figure 6 presents the coefficients of interaction for the $S P 49 / G C 50$ interface as a function of the normal stresses for sand relative densities of $70 \%$ and $90 \%$. As shown previously (Figure 5), the failure envelopes for this interface showed an apparent adhesion, so the coefficient of interaction depends on the normal stress and was 
calculated by Equation (1). For the denser sand $\left(I_{D}=90 \%\right)$, the coefficient of interaction decreased with the confining pressure. The same trend was not achieved for the looser sand $\left(I_{D}=70 \%\right)$ since the peak shear strength of the sand at normal stress of $50 \mathrm{kPa}$ was higher than expected. The direct shear test for sand characterization under normal stress of $50 \mathrm{kPa}$ was repeated several times and the peak shear strength of the sand remained quite similar. Notwithstanding, the shear strength of the sand for confining pressure of $50 \mathrm{kPa}$ reached in direct shear tests performed in a conventional device was $16 \%$ lower than the peak shear strength achieved with the large scale prototype (Vieira, 2008).

Figure 6 shows that the shear strength of the SP49/GC50 interface is lower than the shear strength of the sand. The coefficients of interaction are in the range $0.76-0.94$ for the dense sand $\left(I_{D}=90 \%\right)$ and they ranged from 0.82 to 0.95 for the loose sand $\left(I_{D}=70 \%\right)$. The values of the coefficient of interaction (also called by other authors interface shear strength coefficient or interface efficiency) are consistent with those reported by other researchers for sand/geotextiles interfaces. Abu-Farsakh et al. (2007) reported a coefficient of interaction of 0.74 for a sand/woven geotextile interface while Hsieh et al. (2011) reported a peak friction efficiency of 0.92 for a quartz sand/PP geotextile interface. Silvano and Lopes (2005) found coefficients of interaction ranging from 0.73 to 0.84 for a loose coarse sand/nonwoven geotextile interface. Liu et al.(2009b) reported interface shear strength coefficients ranging from 0.71 to 0.78 for a sand/geotextile interface.

\section{CYCLIC DIRECT SHEAR TESTS}

\subsection{General aspects}

As mentioned in 2.2, the equipment is able to perform displacement or load controlled tests in shear direction. The cyclic direct shear tests presented in this paper were performed with a normal stress of $100 \mathrm{kPa}$ and sinusoidal waveforms shear stresses or displacements. A total of 40 cycles were applied to the interface for each stress (or imposed displacement) level.

For the displacement controlled cyclic direct shear tests, the imposed displacement semi-amplitude, $\Delta_{\mathrm{a}}$, ranged from $0.5 \mathrm{~mm}$ (approximately $7 \%$ of the shear displacement 
for $\tau_{\max }$ under monotonic loading) to the interface strength softening $( \pm 3.5 \mathrm{~mm})$, with $0,25 \mathrm{~mm}$ increments. The failure of the interface was detected by the decrease of the shear stress, for an imposed displacement, with the number of cycles.

For the load controlled cyclic direct shear tests, the imposed shear stress semiamplitude, $\tau_{\mathrm{a}}$, ranged from approximately $20 \%$ of the maximum shear stress reached under monotonic loading ( $\tau_{\max }$ ) to the interface failure with increments of $10 \%$ of $\tau_{\max }$. The failure of the interface was detected when the shear displacements, for an imposed shear stress, increases strongly with the number of cycles.

The applied normal stress, the vertical movements of the loading plate, the shear displacements (imposed in the displacement-controlled tests or resulting in the load controlled tests) and the horizontal shear stress (resulting in the displacement controlled tests or imposed in the load controlled tests) were recorded.

For medium and small strains, the dynamic response of soils is usually characterised through the secant shear modulus and damping ratio, as used in equivalent linear ground motion analyses (Idriss and Seed 1968). This method was modified by Desai et al. (1985) for a sand-concrete interface and applied to a smooth high-density polyethylene geomembrane-geotextile interface by Yegian et al. (1998). A similar analysis is herein presented to characterise the cyclic response of a sand-geosynthetic interface.

For each hysteretic cycle (Figure 7 ), the maximum shear stress, $\tau_{\max , c}$, and the corresponding shear displacement, $\Delta_{\mathrm{hx}}$, the minimum shear stress, $\tau_{\mathrm{min}, \mathrm{c}}$, and the corresponding shear displacement, $\Delta_{\mathrm{hn}}$, the maximum shear displacement, $\Delta_{\mathrm{h}, \max }$, and the minimum shear displacement, $\Delta_{\mathrm{h}, \mathrm{min}}$ were obtained. With these parameters, the interface shear stiffness, $\mathrm{K}$, the damping ratio, $\mathrm{D}$, the displacement semi-amplitude, $\Delta_{\mathrm{a}}$, and the shear stress semi-amplitude, $\tau_{\mathrm{a}}$, are evaluated by the following equations:

$$
\begin{aligned}
& \mathrm{K}=\frac{\tau_{\mathrm{max}, \mathrm{c}}-\tau_{\mathrm{min}, \mathrm{c}}}{\Delta_{\mathrm{hx}}-\Delta_{\mathrm{hn}}} \\
& \mathrm{D}=\frac{\Delta \mathrm{W}}{2 \pi\left(\frac{\tau_{\mathrm{max}, \mathrm{c}}^{2}}{2 \mathrm{~K}}+\frac{\tau_{\mathrm{min}, \mathrm{c}}^{2}}{2 \mathrm{~K}}\right)} \\
& \Delta_{\mathrm{a}}=\frac{\Delta_{\mathrm{h}, \max }-\Delta_{\mathrm{h}, \min }}{2}
\end{aligned}
$$




$$
\tau_{\mathrm{a}}=\frac{\tau_{\max , \mathrm{c}}-\tau_{\min , \mathrm{c}}}{2}
$$

The interface shear stiffness, $\mathrm{K}$, was defined as the slope of the line joining the positive and negative peaks of the shear stress in the $\tau-\Delta_{\mathrm{h}}$ hysteresis loop (Figure 7).

\subsection{Displacement controlled tests}

An example of the response of the sand/geotextile interface to cyclic direct shear is presented in Figure 8. In this cyclic direct shear test, the interface was subjected to 40 cycles of sinusoidal displacement, with semi-amplitude of $2.5 \mathrm{~mm}\left(\Delta_{\mathrm{a}}= \pm 2.5 \mathrm{~mm}\right)$ and frequency of $0.05 \mathrm{~Hz}$. The sand was placed inside the upper shear box with a relative density of $70 \%$. Figure 8 a shows typical shear stress versus shear displacement loop curves for a displacement controlled cyclic direct shear test. The mobilized shear stress increased markedly from the first to the second cycle. For the other cycles, the increase was moderate and reaching almost the stabilization at the end of the test. Mobilized shear stresses are also represented in Figure $8 \mathrm{~b}$ for the complete cyclic test. The minimum shear stress semi-amplitude, $\tau_{\mathrm{a}}$, was $69 \mathrm{kPa}$ for the first cycle, increased to $77 \mathrm{kPa}$ after 10 cycles and remained approximately constant in the subsequent cycles. This shows that the interface response hardens with the number of cycles.

This results are in agreement with results for a sand-concrete interface subjected to translational cyclic loading reported by Desai et al. (1985) which also showed that mobilized shear stress increases with number of cycles, either for loose $\left(I_{D}=15 \%\right)$ or dense sand $\left(I_{D}=80 \%\right)$, although, the increase for the higher density sand was not as expressive as that for the lower density material. Results of cyclic tests presented by Shahrour and Rezaie (1997), performed with a modified direct shear box, to characterise the interfaces between smooth and rough surfaces and loose or dense silica sand, showed an increase of the maximum shear stress with number of cycles (cyclic hardening) for loose sand $\left(I_{D}=15 \%\right)$ and cyclic softening for dense sand $\left(I_{D}=90 \%\right)$.

The influence of the sand relative density on cyclic behaviour of this sand/geotextile interface was also studied in the scope of the present research project and it will be presented in future publications. 
The vertical displacements of the rigid plate centre (or normal displacement) versus the imposed shear displacements are shown in Figure 8c. Initially the first cycle showed a pronounced expansive response as the positive value of the displacement amplitude, $\Delta_{\mathrm{a}}$, was reached. With the reversion of the displacement, a volumetric contraction occurred followed always by some dilative or contractive behaviour, respectively, for positive or negative imposed displacements. However, the contractive behaviour superimposed to the dilative behaviour, so the sample contracted as a result of the induced cycling. The cumulative vertical displacement is equal to $0.9 \mathrm{~mm}$ and $1.1 \mathrm{~mm}$, after 20 cycles and at the end of cyclic loading (40 cycles), respectively.

Figure $8 \mathrm{c}$ shows a progressively decreasing rate of sand densification with the number of cycles similar to the volume change behaviour of sands under simple shear cyclic loading reported by other authors (Silver and Seed 1971; Youd 1972).

The variation of the shear stiffness and the damping ratio with the number of cycles is shown in Figure 9. It is evident that stiffness increased with the number of loading cycles and, on the contrary, the damping ratio tended to decrease. The variation of these parameters after 10 cycles was very slight.

Figure 10 shows the variation of the shear stress semi-amplitude with the shear displacements imposed to the interface after 20 cycles at loading frequency of $0.05 \mathrm{~Hz}$. The rate of shear stress increase recorded after 20 cycles tended to reduce with shear displacement amplitude. This is an evidence of the nonlinear behaviour of the interface.

In direct shear cyclic loading of the interface, the maximum value of the shear strength semi-amplitude was $82.5 \mathrm{kPa}$ (for $\Delta_{\mathrm{a}}= \pm 3.25 \mathrm{~mm}$ ), nearly $15 \%$ larger than the monotonic shear strength of the interface (Figure 4a). It is important to note that the monotonic shear strength represents the maximum shear stress reached for a constant displacement rate of $1 \mathrm{~mm} / \mathrm{min}$, while the cyclic shear strength represents maximum mobilised stress in cycling conditions. Similar behaviour was observed by Desai et al. (1985) on a sand-concrete interface.

The effect of the displacement amplitude and number of cycles on the mobilised shear stress and on the interface shear stiffness is presented in Figure 11. As expected, the semi-amplitude of the shear stress measured at the interface increased with the semiamplitude of the shear displacement, $\Delta_{\mathrm{a}}$, while the interface shear stiffness has the inverse trend. The rate of shear stress increase reduced as the imposed displacement 
increased, therefore the variation of the interface shear stiffness decreases with $\Delta_{\mathrm{a}}$. This variation was particularly significant for the first two displacement stages $\left(\Delta_{\mathrm{a}}= \pm 0.5 \mathrm{~mm}\right.$ and $\left.\Delta_{\mathrm{a}}= \pm 1 \mathrm{~mm}\right)$. The variation of the shear stress amplitude and interface shear stiffness after 10 cycles was almost insignificant.

Figure 12 shows the relations between the interface shear stiffness, $\mathrm{K}$, and the damping ratio, $\mathrm{D}$, with the amplitude of shear displacement, $\Delta_{\mathrm{a}}$, for the $20^{\text {th }}$ cycle. The qualitative trends of the variation of $\mathrm{K}$ and $\mathrm{D}$ with $\Delta_{\mathrm{a}}$ for this sand/geotextile interface were similar to the relations between shear modulus and damping ratio with cyclic shear strain reported by several authors (Seed and Idriss 1970; Ishibashi and Zhang 1993; Vucetic et al. 1998) for cohesionless soils.

Monotonic direct shear tests (with a constant displacement rate of $1 \mathrm{~mm} / \mathrm{min}$ ) were performed after the displacement controlled tests. The effect of the cyclic loading on the interface shear strength is illustrated in Figure 13. Figure 13 presents results of direct shear tests carried out with intact specimens (identified as monotonic), after a displacement controlled test with $\Delta_{\mathrm{a}}= \pm 2.5 \mathrm{~mm}$ and after the interface failure by cyclic loading. The analysis of Figure 13 shows that the cyclic loading did not lead to the peak shear strength degradation, if the cyclic strength of the interface was not reached previously. However, at large displacements, the previous cyclic loading induced some degradation of the interface shear strength, even when the cyclic shear strength of the interface was not reached before. The post-cyclic peak shear strength of the interface was achieved at shear displacements slightly smaller than those required for peak strength of the interface under monotonic loading conditions.

The results of cyclic shear tests between sand and steel surfaces, presented by Fakharian and Evgin (1995), showed that monotonic and cyclic direct shear tests gave the same values of peak and large displacement interface strengths. On the contrary, some degradation of the large displacement shear strength was induced by the cyclic direct shear loading of the interface analysed in this work.

\subsection{Load controlled tests}

The response of the sand/geotextile interface to a load controlled cyclic direct shear test is presented in Figure 14. In this test, the interface was subjected to 40 load cycles with shear stress semi-amplitude of $68.5 \mathrm{kPa}\left(\tau_{\mathrm{a}}= \pm 68.5 \mathrm{kPa}\right)$ with frequency of $0.5 \mathrm{~Hz}$. 
Figure 14a shows typical shear stress versus shear displacement curves for a load controlled cyclic direct shear test. The maximum shear displacement decreased approximately $10 \%$ from the first to the second cycle. The decrease of the maximum shear displacement between other cycles was slight.

Shear displacements for the complete duration of the cyclic test are presented in Figure $14 \mathrm{~b}$. The maximum value of recorded displacement was $3.7 \mathrm{~mm}$, for the first cycle, decreased to $3.2 \mathrm{~mm}$ after 4 cycles and remained approximately constant in the subsequent cycles. This shows, as concluded before for the displacement controlled tests, that the interface response hardened, particularly in the first cycles of loading.

As observed in Figure 14, in load controlled tests, the mean displacement recorded at the interface in each cycle is different from zero. This results, in particular, from the behaviour of the interface in the first load cycle. With the load application the soil hardened and smaller displacements were induced by the same load amplitude, resulting in residual displacements for null shear stresses.

Figure 15 shows the evolution of the shear displacement semi-amplitude with the shear stress applied to the interface after 20 cycles at a frequency of $0.5 \mathrm{~Hz}$. The rate of displacement increase, with the applied shear stress $\tau_{\mathrm{a}}$, was almost constant for the first seven load levels. For the following load levels, with semi-amplitudes lower than the interface monotonic shear strength, the rate of displacement increase raised slightly. When $\tau_{\mathrm{a}}$ reached approximately the maximum shear strength under monotonic loading $\left(\tau_{\max }\right)$, the semi-amplitude of the displacements increased significantly. Nevertheless, the cyclic strength of the interface was attained only for a shear stress $8 \%$ larger than $\tau_{\max }$.

Figure 16 presents the evolution of shear displacements with the number of cycles for distinct values of applied shear stress, $\tau_{\mathrm{a}}$. As previously mentioned for a particular load level (Figure 14), the variation of the shear displacement after 4 cycles of loading was almost insignificant. The hysteretic curves did not suffer significant changes after the first load cycles.

Figure 17 shows the relations between the interface shear stiffness, $\mathrm{K}$, and the damping ratio, $\mathrm{D}$, with the amplitude of shear displacement, $\Delta_{\mathrm{a}}$, for the $20^{\text {th }}$ cycle. The qualitative trends of the variation of $\mathrm{K}$ and $\mathrm{D}$ with $\Delta_{\mathrm{a}}$ are analogous to those presented in Figure 12 for displacement controlled tests. The interface shear stiffness decreased 
significantly with the semi-amplitude of the displacement and the damping ratio showed, as expected, an inverse trend.

The effect of the cyclic loading on the interface shear strength is illustrated in Figure 18. Figure 18 presents the shear stress-shear displacement curves of direct shear tests performed, at constant displacement rate of $1 \mathrm{~mm} / \mathrm{min}$, with intact specimens (identified as monotonic), after a load controlled test with $\tau_{\mathrm{a}}= \pm 46.6 \mathrm{kPa}$ and after the interface failure by cyclic loading (load controlled test). The analysis of this figure leads to analogous conclusions to those presented for the displacement controlled tests (Figure 13). The cyclic loading of the interface did not lead to the degradation of the post-cyclic peak shear strength when the cyclic strength of the interface was not reached previously, but the post-cyclic shear strength for large displacements decreased after cyclic loading.

\subsection{Comparison of displacement and load controlled tests}

Figure 19 compares the secant shear stiffness for the first-quarter cycle obtained by displacement controlled and load controlled tests for the same loading frequency ( $f=0.5 \mathrm{~Hz}$ ). The influence of the cyclic loading type (imposed displacement or applied load) on the stiffness of the first loading was quite insignificant.

The comparison of the shear stiffness and the damping ratio values obtained by displacement controlled and load controlled tests for the $20^{\text {th }}$ cycle is presented in Figure 20. Note that, as previously mentioned, after a few cycles the hysteretic curves remained quite similar, so the results presented in Figure 20 can be considered representative of interface response.

In load controlled tests, very low displacement semi-amplitudes were recorded (less than $0.20 \mathrm{~mm}$ ) in the first stages, therefore very high values of the interface shear stiffness were achieved in this cyclic direct shear tests. Apart from that and neglecting the initial stages, slightly higher values of shear stiffness and damping ratio were reached with displacement controlled cyclic direct shear tests.

\section{CONCLUSIONS}

The behaviour of an interface between a silica poorly graded sand and a high strength geotextile was characterized through monotonic and cyclic direct shear tests. 
Based on the analysis and interpretation of the direct shear test results, the following conclusions are drawn.

i) The coefficients of interaction obtained in monotonic tests for this sand/geotextile interface depend on the confining pressure;

ii) In direct shear cyclic tests the interface stiffness tended to increase during the first loading cycles, suffering slight variations after 10 cycles;

iii) The interface stiffness for the first loading of the interface, achieved with displacement or load controlled cyclic direct shear tests was quite similar;

iv) For nearly the same shear displacement amplitude, slightly higher values of shear stiffness and damping ratio were reached with displacement controlled cyclic direct shear tests when compared with load controlled tests;

v) The cyclic loading of the interface did not lead to the degradation of its peak shear strength when the cyclic strength of the interface was not reached previously. However, at large displacements, the previous cyclic loading induced some degradation of the interface shear strength, even when the cyclic shear strength of the interface was not reached before.

Cyclic direct shear tests performed at different frequencies showed that the cyclic behaviour of the interface is not significantly affected by the frequency (for the range of frequencies tested: $0.005 \mathrm{~Hz}-0.5 \mathrm{~Hz}$ ). The effect of frequency and sand relative density on the cyclic behaviour of this sand/geotextile interface can be found in Vieira (2008).

\section{ACKNOWLEDGMENTS}

The authors would like to thank the financial support of Portuguese Science and Technology Foundation (FCT) and FEDER, Research Project FCOMP-01-0124FEDER-009750 - PTDC/ECM/100975/2008.

\section{REFERENCES}

Abu-Farsakh, M., Coronel, J. \& Tao, M. (2007). Effect of soil moisture content and dry density on cohesive soil-geosynthetic interactions using large direct shear tests. Journal of Materials in Civil Engineering, 19(7), 540-549.

Anubhav \& Basudhar, P. K. (2010). Modeling of soil-woven geotextile interface behavior from direct shear test results. Geotextiles and Geomembranes, 28(4): 403-408. 
ASTM D 5321 (2002) Standard test method for determining the coefficient of soil and geosynthetic or geosynthetic and geosynthetic friction by the direct shear method, American Society for Testing Materials, USA.

Bakeer, R. M., Sayed, M., Cates, P. \& Subramanian, R. (1998). Pullout and shear test on geogrid reinforced lightweight aggregate. Geotextiles and Geomembranes, 16(2), 119-133.

Bemben, S. M. \& Schulze, D. A. (1998). The influence of equipment style and setup dimensions on sand/geomembrane direct shear test measurement, in: 6th International Conference on Geosynthetics, Atlanta, USA, 453-458.

Cazzuffi, D., Picarelli, L., Ricciuti, A.\& Rimoldi, P. (1993). Laboratory investigations on the shear strength of geogrid reinforced soils, in: Geosynthetic Soil Reinforcement Testing Procedures, ASTM STP 1190, Philadelphia.

Chenggang, B. (2004). Study on the interaction behavior of geosynthetics and soil in China, in: GeoAsia 04 - Asian Regional Conference on Geosynthetics, Seoul, Korea, 104-115.

De, A. (1996). Study of interfacial friction of landfill geosynthetics: Static and dynamic. PhD Thesis, Rensselaer Polytechnic Institute, United States - New York, $245 \mathrm{p}$.

De, A. \& Zimmie, T. F. (1998). Estimation of dynamic interfacial properties of geosynthetics. Geosynthetics International. Special Issue on Geosynthetics in Earthquake Engineering, 5(1-2): 17-39.

Desai, C. S., Drumm, E. C. \& Zaman, M. M. (1985). Cyclic testing and modeling of interfaces. Journal of Geotechnical Engineering, ASCE, 111(6), 793-815.

EN ISO 12957-1, 2005, Geosynthetics - Determination of the friction characteristics - Part 1: Direct shear test, CEN - TC 189, 11p.

Fakharian, K. \& Evgin, E. (1995). Simple shear versus direct shear tests on interfaces during cyclic loading, in: Proc. 3rd Int. Conf. on Recent Advances in Geotechnical Engineering and Soil Dynamics, Vol. 1, St. Louis, MO, 13-16.

Fannin, R. J. \& Raju, D. M., 1993. On the pullout resistance of geosynthetics. Canadian Geotechnical Journal, 30, 409-417. 
FHWA (2010). Design and Construction of Mechanically Stabilized Earth Walls and Reinforced Soil Slopes, Geotechnical Engineering Circular No. 11 FHWA-NHI-10-024 Federal Highway Administration, US Department of Transportation, Washington D.C.

Fox, P. J., Ross, J. D., Sura, J. M. \& Thiel, R. S. (2011). Geomembrane damage due to static and cyclic shearing over compacted gravelly sand. Geosynthetics International, $18(5), 272-279$.

Hsieh, C. \& Hsieh, M.-W. (2003). Load plate rigidity and scale effects on the frictional behavior of sand/geomembrane interfaces. Geotextiles and Geomembranes, $21,25-47$.

Hsieh, C. W., Chen, G. H. \& Wu, J.-H. (2011). The shear behavior obtained from the direct shear and pullout tests for different poor grades soil-geosynthetic systems Journal of GeoEngineering, 6(1), 15-26.

Idriss, I. M. \& Seed, H. B. (1968). Seismic response of horizontal soil layers. Journal of Soil Mechanics and Foundations Division, 94(4), 1003-1031.

Imaizumi, S., Nishigata, T. \& Imura, K. (1994). Effect of variation in sample sizes on soil-polymer interface strength, in: Fifth International Conference on Geotextiles, Geomembranes and Related Products, Singapore, 5-9 September, 423-426.

Ingold, T. S. (1982). Some observations on the laboratory measurement of soilgeotextile bound. Geotechnical Testing Journal, 5(3), 57-67.

Ishibashi, I. \& Zhang, X. (1993). Unified dynamic shear moduli and damping ratios of sand and clay. Soils and Foundations, 33(1): 182-191.

Khoury, C. N., Miller, G. A. \& Hatami, K. (2011). Unsaturated soil-geotextile interface behavior. Geotextiles and Geomembranes, 29(1): 17-28.

Kim, J., Riemer, M. \& Bray, J. D. (2005). Dynamic properties of geosynthetic interfaces. Geotechnical Testing Journal, 28(3), 1-9.

Lee, K. M. \& Manjunath, V. R. (2000). Soil-geotextile interface friction by direct shear tests. Canadian Geotechnical Journal, 37, 238-252.

Ling, H. I., Burke, C., Mohri, Y. \& Matsushima, K. (2002). Shear Strength Parameters of Soil-Geosynthetic Interfaces Under Low Confining Pressure Using a Tilting Table. Geosynthetics International, 9(4): 373-380. 
Ling, H. I., Wang, J.-P. \& Leshchinsky, D. (2008). Cyclic behaviour of soil-structure interfaces associated with modular-block reinforced soil-retaining walls. Geosynthetics International, 15(1), 14-21.

Liu, C.-N., Ho, Y.-H.\& Huang, J.-W., (2009a). Large scale direct shear tests of soil/PET-yarn geogrid interfaces. Geotextiles and Geomembranes, 27(1), 19-30.

Liu, C.-N., Zornberg, J. G., Chen, T.-C., Ho, Y.-H. \& Lin, B.-H. (2009b). Behavior of geogrid-sand interface in direct shear mode. Journal of Geotechnical and Geoenvironmental Engineering, 135(12): 1863-1871.

Mayer, N., Nernheim, A. \& Kohler, U. (2004). Geosynthetic-soil interaction under cyclic loading, in: 3rd European Geosynthetics Conference, Munich, Germany, 01-03 March, 635-639.

Min, Y., Leshchinsky, D., Ling, H. I. \& Kaliakin, V. N. (1995). Effects of Sustained and Repeated Tensile Loads on Geogrid Embedded in Sand. Geotechnical Testing Journal, 18(2), 204-225.

Moraci, N. \& Cardile, G. (2009). Influence of cyclic tensile loading on pullout resistance of geogrids embedded in a compacted granular soil. Geotextiles and Geomembranes, 27(6), 475-487.

Nakamura, T., Mitachi, T. \& Ikeura, I. (1999). Direct shear testing method as a means for estimating geogrid-sand Interface shear - displacement behavior. Soils and Foundations, 39(4), 1-8.

Nye, C. J. \& Fox, P. J. (2007). Dynamic shear behavior of a needle-punched Geosynthetic Clay Liner. Journal of Geotechnical and Geoenvironmental Engineering, 133(8), 973-983.

O'Rourke, T. D., Druschel, S. J. \& Netravali, A. N. (1990). Shear strength characteristics of sand-polymer interfaces. Journal of Geotechnical Engineering, ASCE, 116(3), 451-469.

Palmeira, E. M. (1987). The study of soil-reinforcement interaction by means of large scale laboratory tests. $\mathrm{PhD}$ Thesis, University of Oxford, $236 \mathrm{p}$.

Palmeira, E. M. (1988). Discussion on direct shear tests on reinforced sand. Geotechnique, 38(1), 146-148.

Palmeira, E. M. (2009). Soil-geosynthetic interaction: modelling and analysis. Geotextiles and Geomembranes, 27, 368-390. 
Seed, H. B. \& Idriss, I. M. (1970). Soil moduli and damping factors for dynamic response analysis. Earthquake Engineering Research Center, University of California, Berkeley, Report No. UCB/EERC-70/10, 48 p.

Shahrour, I.\& Rezaie, F. (1997). An elastoplastic constitutive relation for the soilstructure interface under cyclic loading. Computers and Geotechnics, 21(1), 21-39.

Silvano, R. P. S. X. \& Lopes, M. L. (2005). Soil/geosynthetic interface characterization trough direct shear tests, in: 6th International Conference on Ground Improvement Techniques, Coimbra, Portugal, 555-560.

Silvano, R. P. S. X. (2005). Geosynthetic reinforced soil. Study of behaviour characterizing parameters. MsC Thesis, Faculty of Science, University of Coimbra, $185 \mathrm{p}$ (in Portuguese).

Silver, N. L. \& Seed, H. B. (1971). Volume changes in sands during cyclic loading. Journal of the Soil Mechanics and Foundations Division, ASCE, 97(SM9), 1171-1182.

Stoewahse, C., Dixon, N., Jones, D. R. V., Blumel, W. \& Kamugisha, P. (2002). Geosynthetic interface shear behaviour: Part 1 - Test methods. Ground Engineering, 3541.

Vieira, C. S. (2008). Geosynthetic reinforced soil retaining walls and slopes. Seismic behaviour and design methodologies. PhD Thesis, Civil Engineering Department, University of Porto, $575 \mathrm{p}$ (in Portuguese).

Vucetic, M., Lanzo, G. \& Doroudian, M. (1998). Damping at small strains in cyclic simple shear test Journal of Geotechnical \& Geoenvironmental Engineering, 124(7): 585-594.

Yasuda, S., Nagase, H. \& Marui, H. (1992). Cyclic pullout tests of geogrids in soils, in: Proc. of the International Symposium on Earth Reinforced Practice, IS-Kyushu'92, Vol. 1, Fukuoka, Japan, 185-190.

Yegian, M. K. \& Kadakal, U. (1998). Geosynthetic interface behavior under dynamic loading. Geosynthetics International. Special Issue on Geosynthetics in Earthquake Engineering, 5(1-2): 1-16.

Yegian, M. K. \& Lahlaf, A. M. (1992). Dynamic interface shear strength properties of geomembranes and geotextiles. Journal of Geotechnical Engineering, ASCE, 118(5), 760-779. 
Sand-geotextile interface characterisation through monotonic and cyclic direct shear tests. Geosynthetics International, 20, No. 1, 26-38. DOI: 10.1680/gein.12.00037

Yegian, M. K., Harb, J. N. \& Kadakal, U. (1998). Dynamic response analysis procedure for landfills with geosynthetic liners. Journal of Geotechnical and Geoenvironmental Engineering, 124(10), 1027-1033.

Yegian, M. K., Yee, Z. Y. \& Harb, J. N. (1995). Seismic response of geosynthetic soil systems, in: Geoenvironment 2000, Geotechnical Special Publication N. ${ }^{\text {46, }}$ ASCE, Vol. 2, New Orleans, Louisiana, USA, 1113-1125.

Youd, T. L. (1972). Compaction of sands by repeated shear straining. Journal of the Soil Mechanics and Foundations Division, ASCE, 98(7), 709-725. 


\section{NOTATIONS}

Basic SI units are given in parentheses.

$\mathrm{c}$ - soil cohesion $(\mathrm{Pa})$

$\mathrm{c}_{\mathrm{a}}$ - apparent adhesion $(\mathrm{Pa})$

$\mathrm{c}_{\mathrm{a}, \mathrm{cv}}$ - apparent adhesion corresponding to large displacement shear strength $(\mathrm{Pa})$

$\mathrm{c}_{\mathrm{a}, \mathrm{p}}$ - apparent adhesion corresponding to the peak shear strength $(\mathrm{Pa})$

D - damping ratio (dimensionless)

$f_{g}$ - coefficient of interaction or friction ratio (dimensionless)

$\mathrm{I}_{\mathrm{D}}$ - relative density or density index (dimensionless)

$\mathrm{K}$ - interface shear stiffness $(\mathrm{Pa} / \mathrm{m})$

$\mathrm{K}_{1}$ - interface shear stiffness for the first cycle $(\mathrm{Pa} / \mathrm{m})$

$\mathrm{S}$ - shear force $(\mathrm{N})$

\section{Greek letters}

$\Delta_{\mathrm{a}}$ - semi-amplitude of the shear displacement (m)

$\Delta_{\mathrm{h}}$ - shear displacement (m)

$\Delta_{\mathrm{hx}}$ - shear displacement for $\tau_{\max }(\mathrm{m})$

$\delta$ - interface friction angle $\left(^{\circ}\right)$

$\delta_{\mathrm{cv}}$ - interface friction angle for large relative displacements (degrees)

$\delta_{\mathrm{p}}$ - interface peak friction angle (degrees)

$\tau_{\mathrm{a}}$ - semi-amplitude of the shear stress $(\mathrm{Pa})$

$\tau_{\max }$ - maximum shear stress under monotonic loading $(\mathrm{Pa})$

$\tau_{40 \mathrm{~mm}}$ - shear stress for $40 \mathrm{~mm}$ of relative displacement (m)

$\tau_{\mathrm{soil}}^{\max }(\sigma)$ - maximum shear stress in a direct shear test on soil (Pa)

$\tau_{\text {soil/geo }}^{\max }(\sigma)$ - maximum shear stress in a soil/geosynthetic direct shear test $(\mathrm{Pa})$

$\sigma$ - normal stress $(\mathrm{Pa})$

$\phi$ - soil internal friction angle (degrees) 


\section{LIST OF FIGURES}

Figure 1. Potential failure mechanism of a reinforced soil slope and the most suitable laboratory tests to soil-reinforcement characterization (modified from Nakamura et al. 1999).

Figure 2. Overall view of the direct shear test device.

Figure 3. Appraisal of the tests results reproducibility (sand/geotextile interface)

Figure 4. Monotonic direct shear tests of SP49/GC50 interface for different normal stresses (50, 100 and $150 \mathrm{kPa}$ ): (a) shear stress-shear displacement; (b) vertical displacement (settlement)-shear displacement.

Figure 5. Peak and large displacement shear strengths as a function of the applied normal stress $\left(I_{D}=70 \%\right)$.

Figure 6. Coefficient of interaction against normal stress for sand relative densities of $70 \%$ and $90 \%$.

Figure 7. Definition of interface shear stiffness and energy dissipation.

Figure 8. Displacement controlled cyclic direct shear test $\left(\Delta_{\mathrm{a}}= \pm 2.5 \mathrm{~mm}, \mathrm{f}=0.05 \mathrm{~Hz}\right)$ :

(a) shear stress versus shear displacement; (b) evolution of shear stress along time;

(c) vertical displacement versus shear displacement

Figure 9. Variation of shear stiffness and damping ratio with the number of cycles $\left(\Delta_{\mathrm{a}}= \pm 2.5 \mathrm{~mm}, \mathrm{f}=0.05 \mathrm{~Hz}\right)$.

Figure 10. Variation of shear stress semi-amplitude with imposed shear displacement after 20 cycles $(f=0.05 \mathrm{~Hz})$.

Figure 11. Effect of cyclic shear displacement amplitude and number of cycles ( $f=0.05 \mathrm{~Hz}$ ) on: a) mobilized shear stress; b) interface shear stiffness.

Figure 12. Variation of shear stiffness and damping ratio with shear displacement after 20 cycles $(f=0.05 \mathrm{~Hz})$.

Figure 13. Effect of cyclic loading on the interface shear strength (after displacement controlled tests, $\mathrm{f}=0.05 \mathrm{~Hz}$ ).

Figure 14. Load controlled cyclic direct shear test $\left(\tau_{\mathrm{a}}= \pm 68.5 \mathrm{kPa}, \mathrm{f}=0.5 \mathrm{~Hz}\right)$ : (a) shear stress versus shear displacement; (b) variation of shear displacement with time

Figure 15. Evolution of the semi-amplitude of displacement with applied shear stress after 20 cycles. 
Sand-geotextile interface characterisation through monotonic and cyclic direct shear tests. Geosynthetics International, 20, No. 1, 26-38. DOI: 10.1680/gein.12.00037

Figure 16. Evolution of shear displacement semi-amplitude with the number of cycles for distinct values of $\tau_{\mathrm{a}}(\mathrm{f}=0.5 \mathrm{~Hz})$.

Figure 17. Variation of interface shear stiffness and damping ratio with the semiamplitude of shear displacement $(f=0.5 \mathrm{~Hz})$ after 20 cycles.

Figure 18. Effect of cyclic loading on the interface shear strength (load controlled tests, $\mathrm{f}=0.5 \mathrm{~Hz})$.

Figure 19. Comparison of the secant shear stiffness for the first cycle obtained by displacement and load controlled tests $(f=0.5 \mathrm{~Hz})$.

Figure 20. Comparison of results obtained by displacement and load controlled tests after 20 cycles $(f=0.5 \mathrm{~Hz})$ : a) interface shear stiffness; $b$ ) damping ratio. 
Sand-geotextile interface characterisation through monotonic and cyclic direct shear tests. Geosynthetics International, 20, No. 1, 26-38. DOI: 10.1680/gein.12.00037

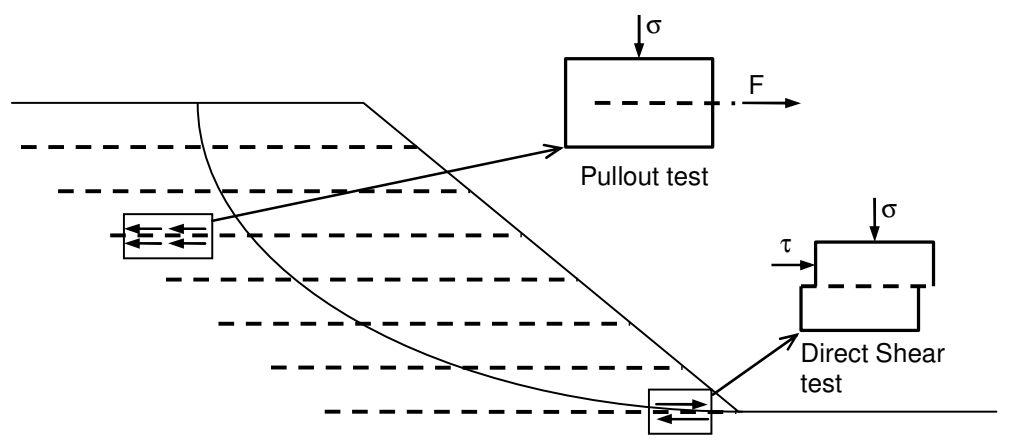

Figure 1. Potential failure mechanism of a reinforced soil slope and the most suitable laboratory tests to soil-reinforcement characterization (modified from Nakamura et al. 1999). 
This manuscript is the accepted version of the paper:

Sand-geotextile interface characterisation through monotonic and cyclic direct shear tests. Geosynthetics International, 20, No. 1, 26-38. DOI: 10.1680/gein.12.00037

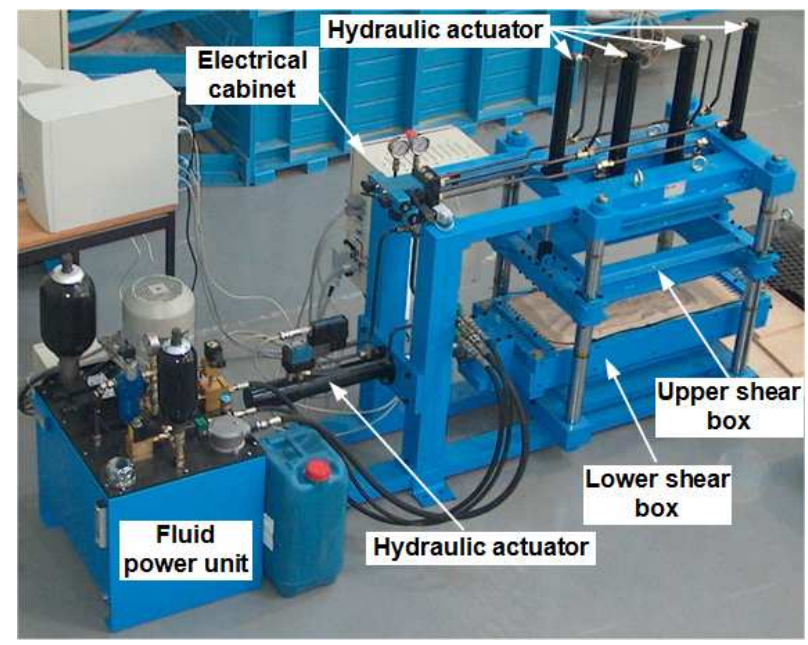

Figure 2. Overall view of the direct shear test device. 
This manuscript is the accepted version of the paper:

Sand-geotextile interface characterisation through monotonic and cyclic direct shear tests. Geosynthetics International, 20, No. 1, 26-38. DOI: 10.1680/gein.12.00037

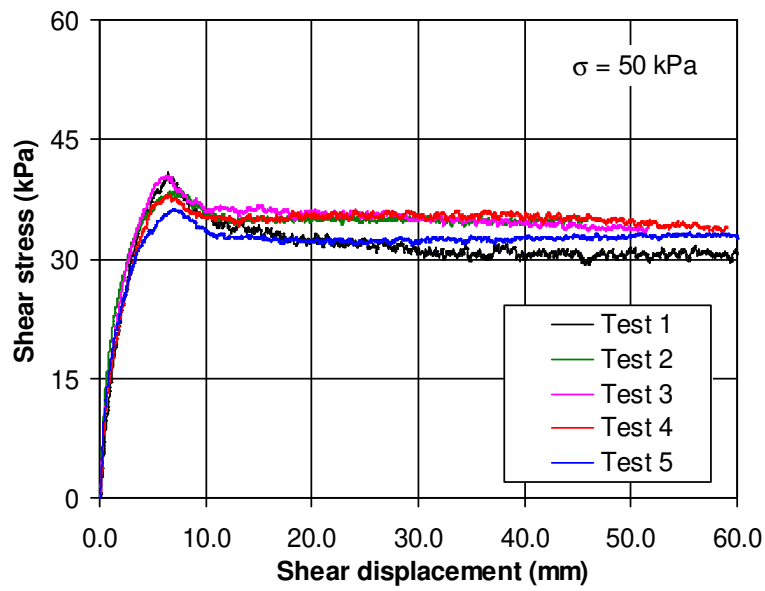

Figure 3. Appraisal of the test results reproducibility (sand/geotextile interface). 
This manuscript is the accepted version of the paper:

Sand-geotextile interface characterisation through monotonic and cyclic direct shear tests. Geosynthetics International, 20, No. 1, 26-38. DOI: 10.1680/gein.12.00037
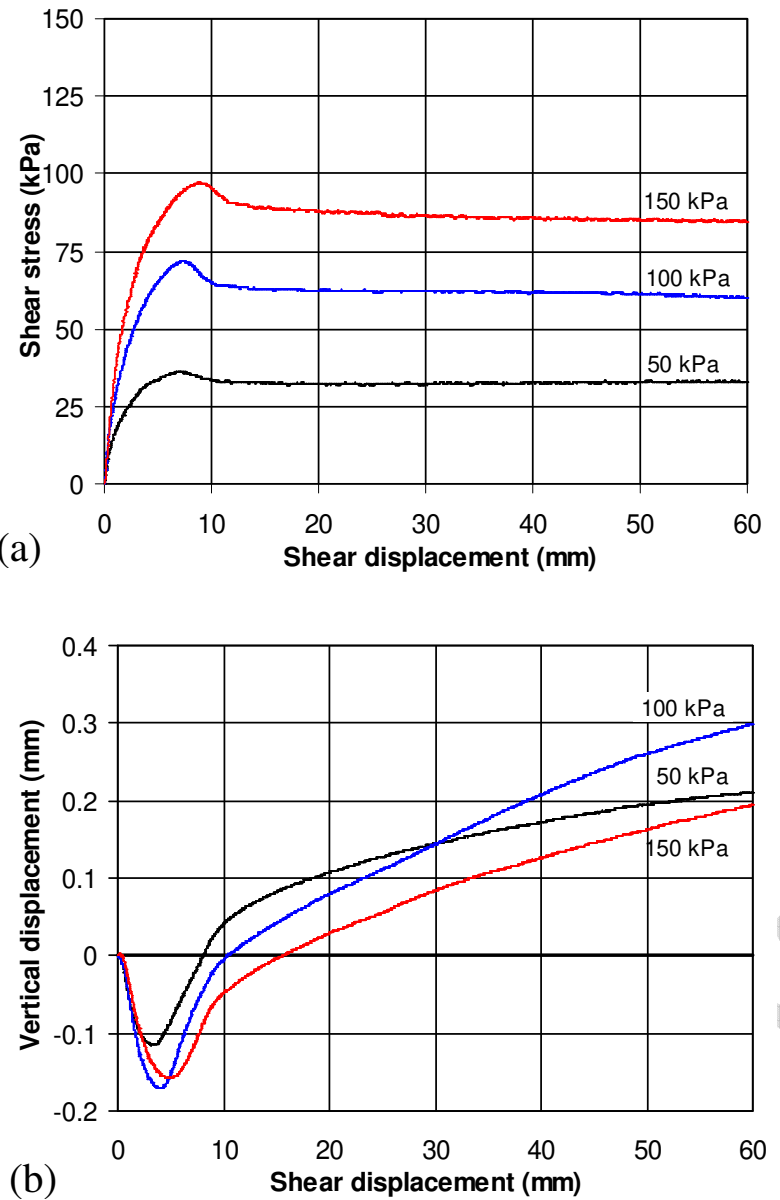

Figure 4. Monotonic direct shear tests of $S P 49 / G C 50$ interface for different normal stresses (50, 100 and $150 \mathrm{kPa})$ : (a) shear stress-shear displacement; (b) vertical displacement (settlement)-shear displacement. 
This manuscript is the accepted version of the paper:

Sand-geotextile interface characterisation through monotonic and cyclic direct shear tests. Geosynthetics International, 20, No. 1, 26-38. DOI: 10.1680/gein.12.00037

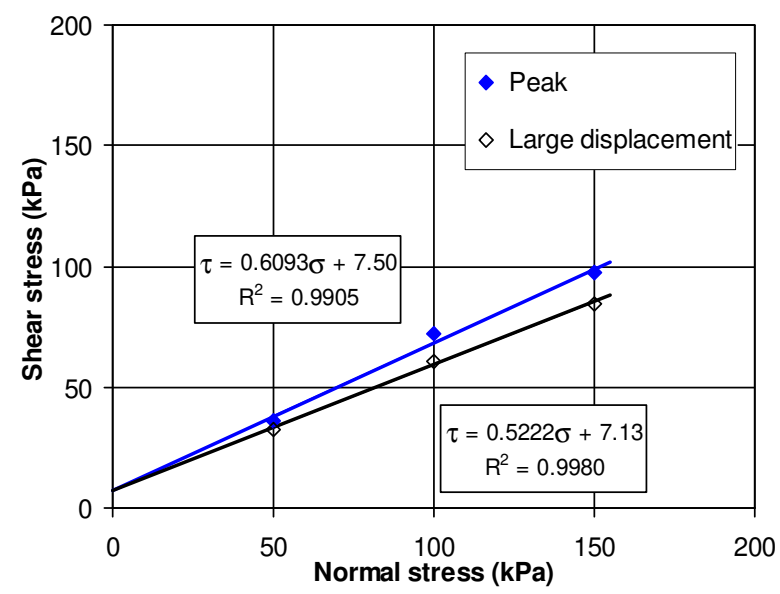

Figure 5. Peak and large displacement shear strengths as a function of the applied normal stress $\left(I_{D}=70 \%\right)$. 
This manuscript is the accepted version of the paper:

Sand-geotextile interface characterisation through monotonic and cyclic direct shear tests. Geosynthetics International, 20, No. 1, 26-38. DOI: 10.1680/gein.12.00037

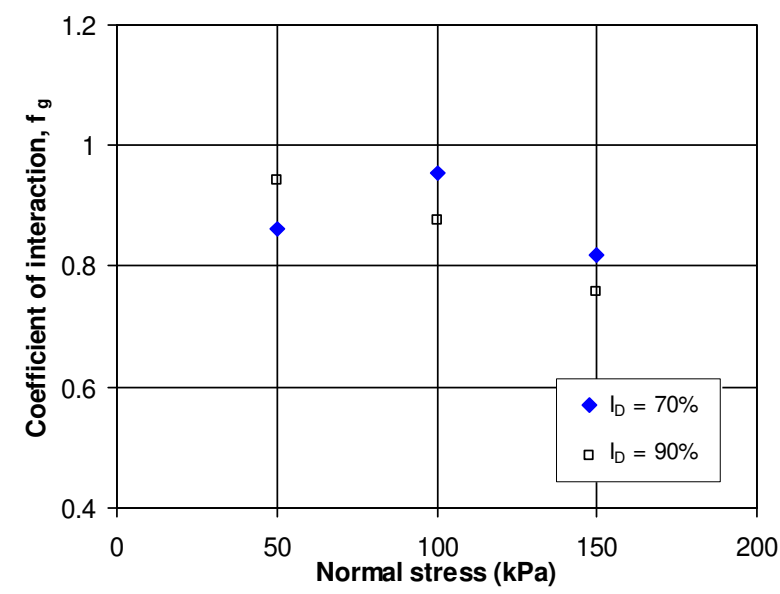

Figure 6. Coefficient of interaction against normal stress for sand relative densities of $70 \%$ and $90 \%$. 
This manuscript is the accepted version of the paper:

Sand-geotextile interface characterisation through monotonic and cyclic direct shear tests. Geosynthetics International, 20, No. 1, 26-38. DOI: 10.1680/gein.12.00037

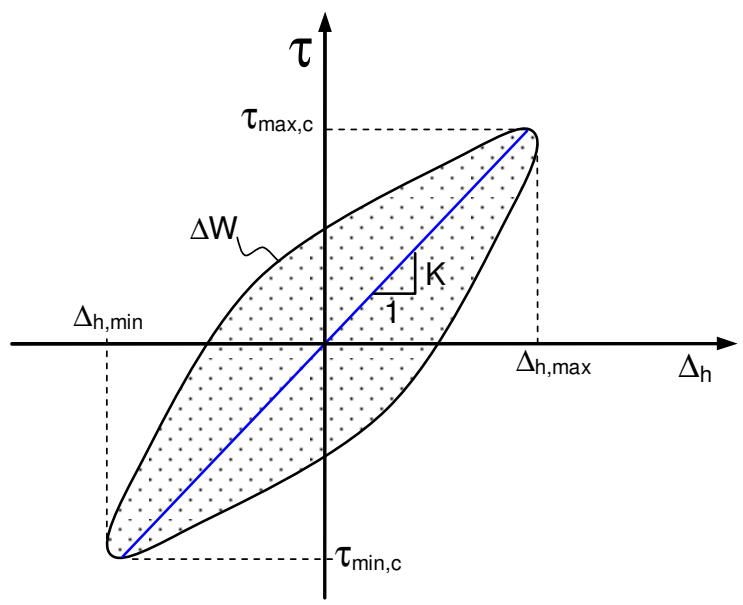

Figure 7. Definition of interface shear stiffness and energy dissipation. 
This manuscript is the accepted version of the paper:

Sand-geotextile interface characterisation through monotonic and cyclic direct shear tests. Geosynthetics International, 20, No. 1, 26-38. DOI: 10.1680/gein.12.00037

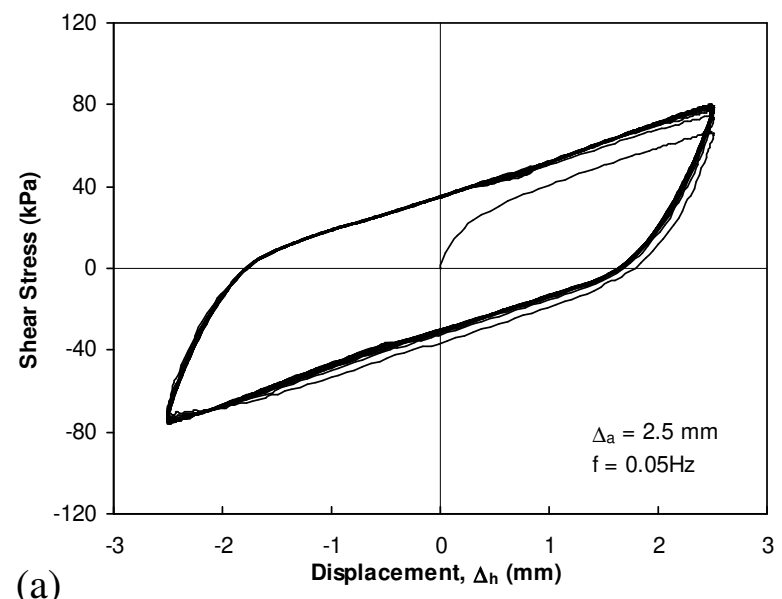

(a)
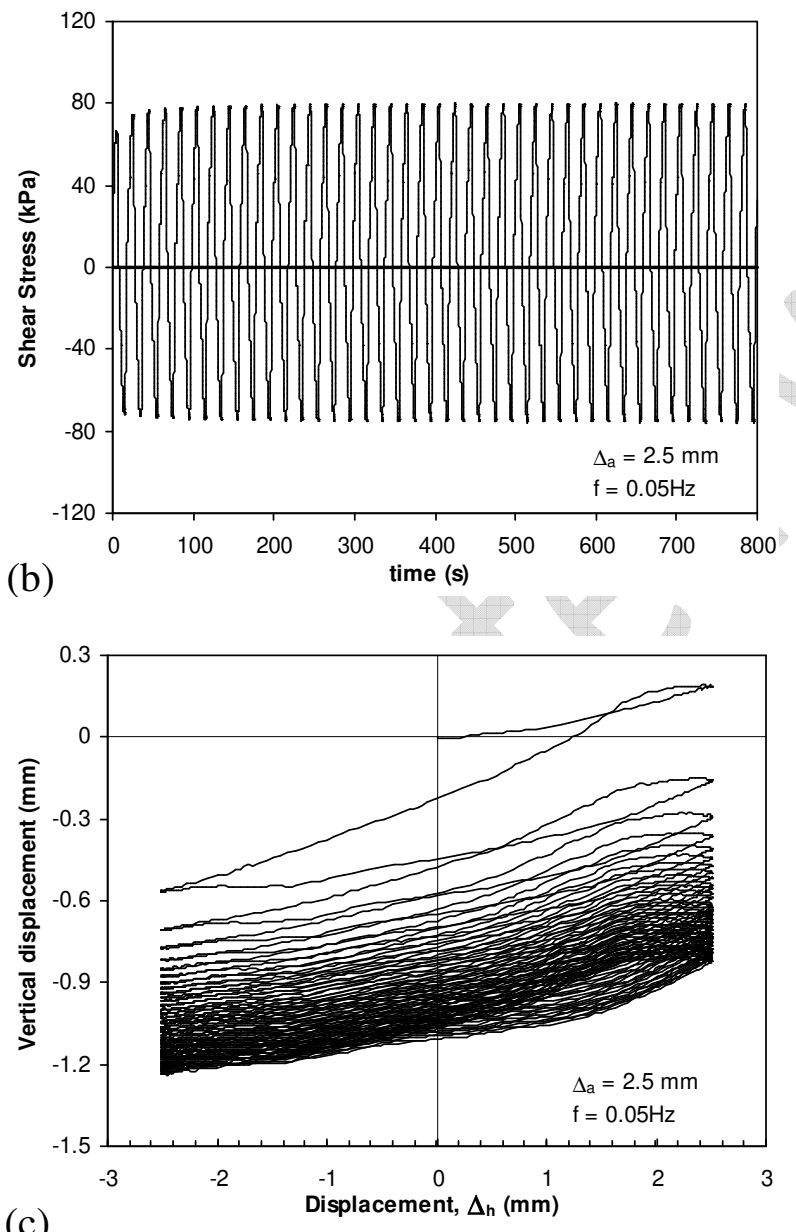

(c)

Figure 8. Displacement controlled cyclic direct shear test $\left(\Delta_{\mathrm{a}}= \pm 2.5 \mathrm{~mm}, \mathrm{f}=0.05 \mathrm{~Hz}\right)$ :

(a) shear stress versus shear displacement; (b) evolution of shear stress along time;

(c) vertical displacement versus shear displacement. 
This manuscript is the accepted version of the paper:

Sand-geotextile interface characterisation through monotonic and cyclic direct shear tests. Geosynthetics International, 20, No. 1, 26-38. DOI: 10.1680/gein.12.00037

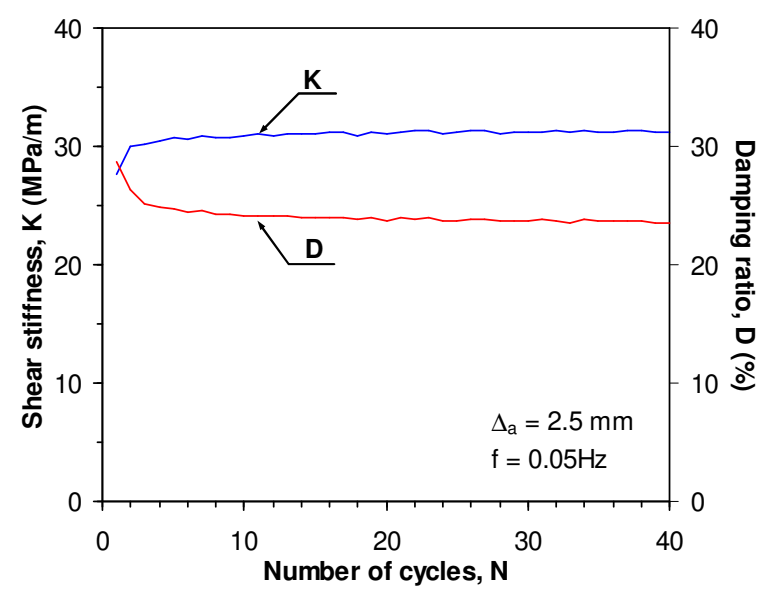

Figure 9. Variation of shear stiffness and damping ratio with the number of cycles $\left(\Delta_{\mathrm{a}}= \pm 2.5 \mathrm{~mm}, \mathrm{f}=0.05 \mathrm{~Hz}\right)$. 
This manuscript is the accepted version of the paper:

Sand-geotextile interface characterisation through monotonic and cyclic direct shear tests. Geosynthetics International, 20, No. 1, 26-38. DOI: 10.1680/gein.12.00037

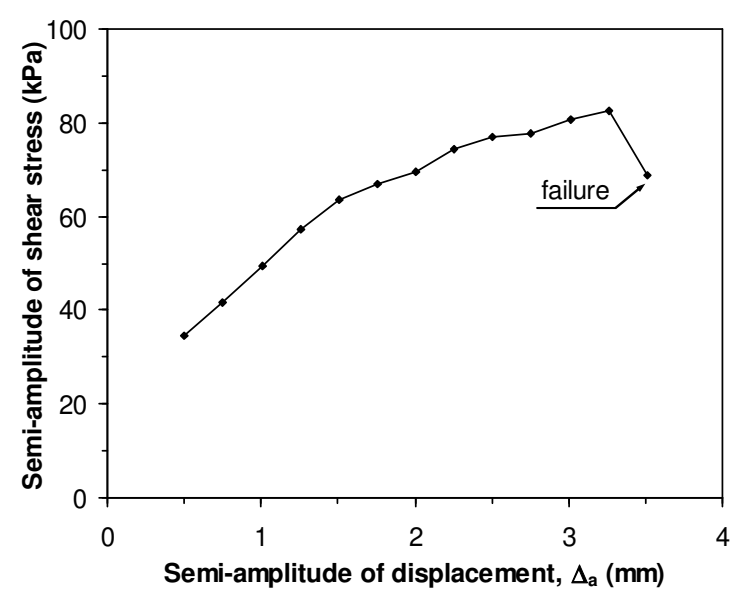

Figure 10. Variation of shear stress semi-amplitude with imposed shear displacement after 20 cycles $(f=0.05 \mathrm{~Hz})$. 
This manuscript is the accepted version of the paper:

Sand-geotextile interface characterisation through monotonic and cyclic direct shear tests. Geosynthetics International, 20, No. 1, 26-38. DOI: 10.1680/gein.12.00037
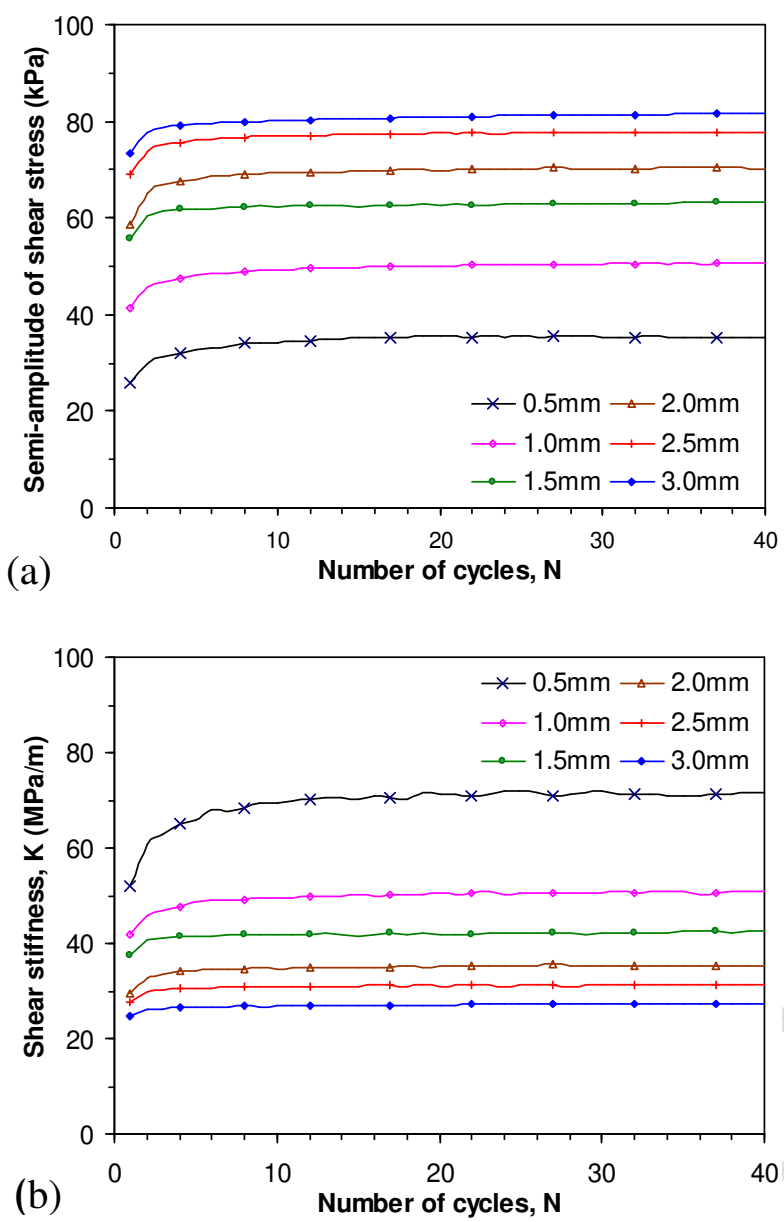

Figure 11. Effect of cyclic shear displacement amplitude and number of cycles ( $f=0.05 \mathrm{~Hz})$ on: a) mobilized shear stress; b) interface shear stiffness. 
This manuscript is the accepted version of the paper:

Sand-geotextile interface characterisation through monotonic and cyclic direct shear tests. Geosynthetics International, 20, No. 1, 26-38. DOI: 10.1680/gein.12.00037

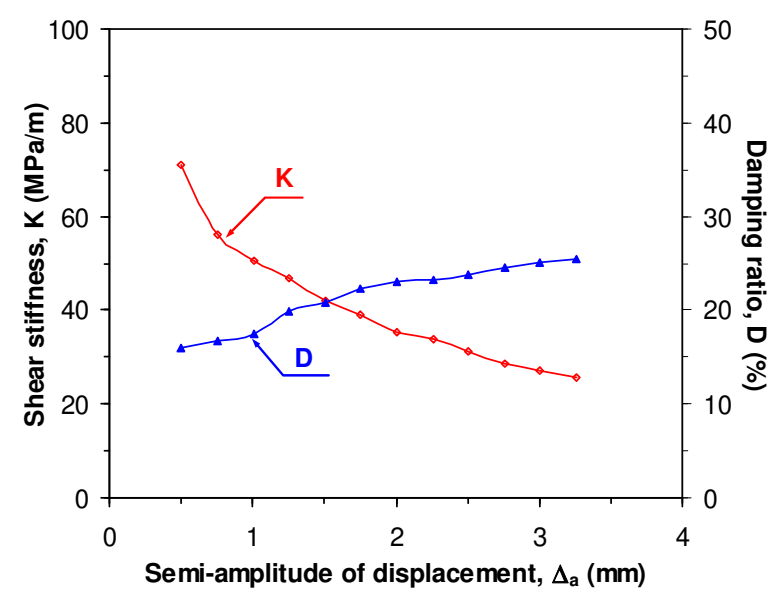

Figure 12. Variation of shear stiffness and damping ratio with shear displacement after 20 cycles $(f=0.05 \mathrm{~Hz})$. 
This manuscript is the accepted version of the paper:

Sand-geotextile interface characterisation through monotonic and cyclic direct shear tests. Geosynthetics International, 20, No. 1, 26-38. DOI: 10.1680/gein.12.00037

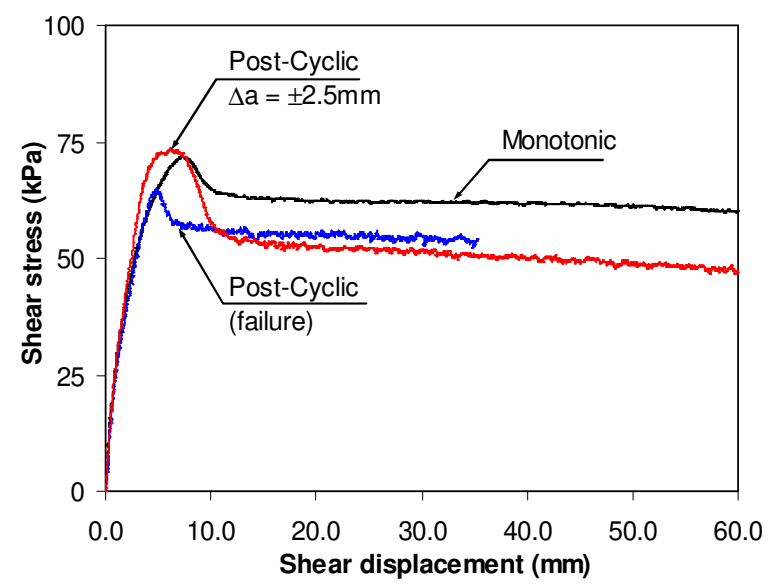

Figure 13. Effect of cyclic loading on the interface shear strength (after displacement controlled tests, $\mathrm{f}=0.05 \mathrm{~Hz}$ ). 
This manuscript is the accepted version of the paper:

Sand-geotextile interface characterisation through monotonic and cyclic direct shear tests. Geosynthetics International, 20, No. 1, 26-38. DOI: 10.1680/gein.12.00037

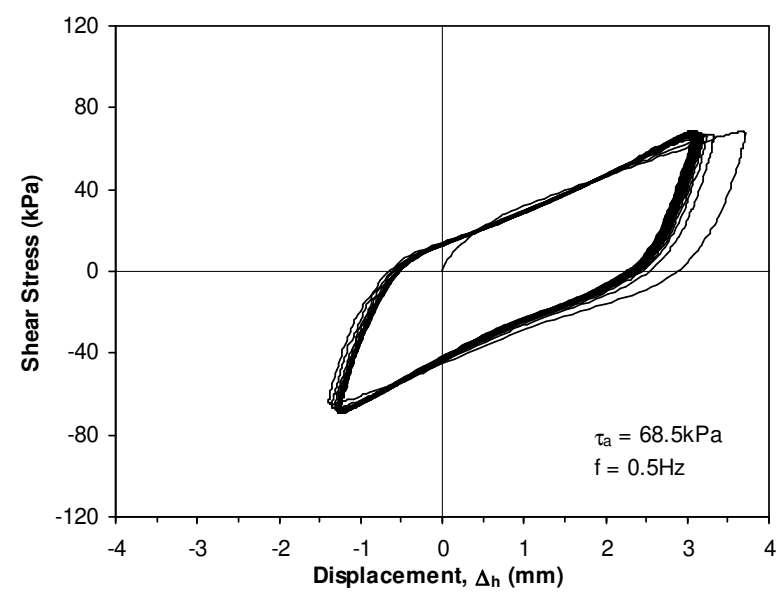

(a)

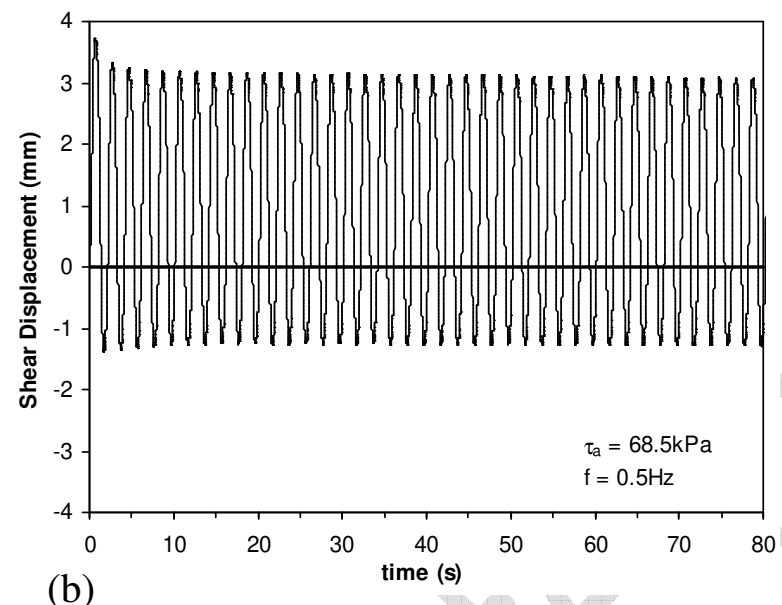

Figure 14. Load controlled cyclic direct shear test $\left(\tau_{\mathrm{a}}= \pm 68.5 \mathrm{kPa}, \mathrm{f}=0.5 \mathrm{~Hz}\right):$ (a) shear stress versus shear displacement; (b) variation of shear displacement with time. 
This manuscript is the accepted version of the paper:

Sand-geotextile interface characterisation through monotonic and cyclic direct shear tests. Geosynthetics International, 20, No. 1, 26-38. DOI: 10.1680/gein.12.00037

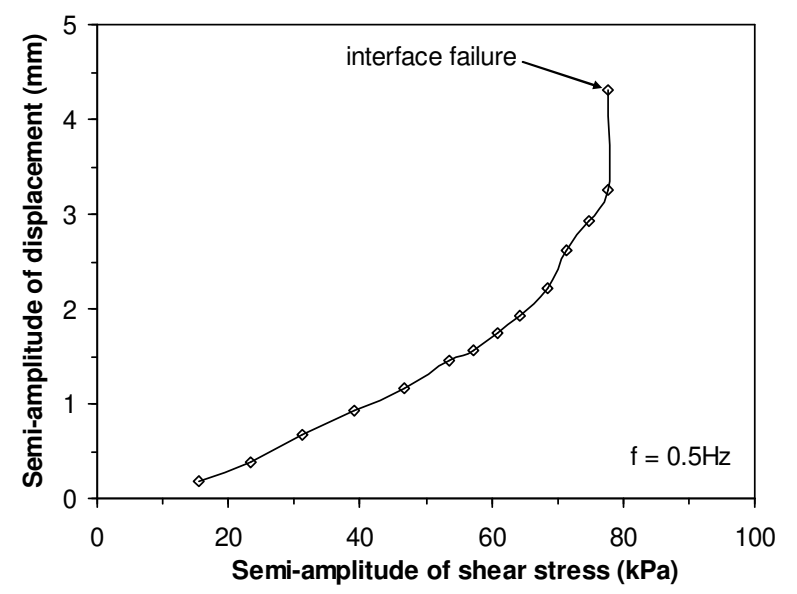

Figure 15. Evolution of the semi-amplitude of displacement with applied shear stress after 20 cycles. 
This manuscript is the accepted version of the paper:

Sand-geotextile interface characterisation through monotonic and cyclic direct shear tests. Geosynthetics International, 20, No. 1, 26-38. DOI: 10.1680/gein.12.00037

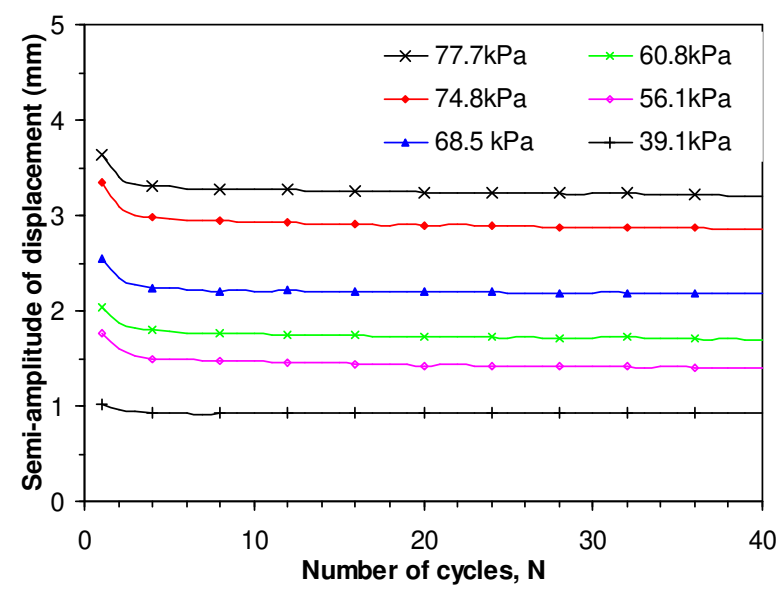

Figure 16. Evolution of shear displacement semi-amplitude with the number of cycles for distinct values of $\tau_{\mathrm{a}}(\mathrm{f}=0.5 \mathrm{~Hz})$. 
This manuscript is the accepted version of the paper:

Sand-geotextile interface characterisation through monotonic and cyclic direct shear tests. Geosynthetics International, 20, No. 1, 26-38. DOI: 10.1680/gein.12.00037



Figure 17. Variation of interface shear stiffness and damping ratio with the semiamplitude of shear displacement $(f=0.5 \mathrm{~Hz})$ after 20 cycles. 
This manuscript is the accepted version of the paper:

Sand-geotextile interface characterisation through monotonic and cyclic direct shear tests. Geosynthetics International, 20, No. 1, 26-38. DOI: 10.1680/gein.12.00037

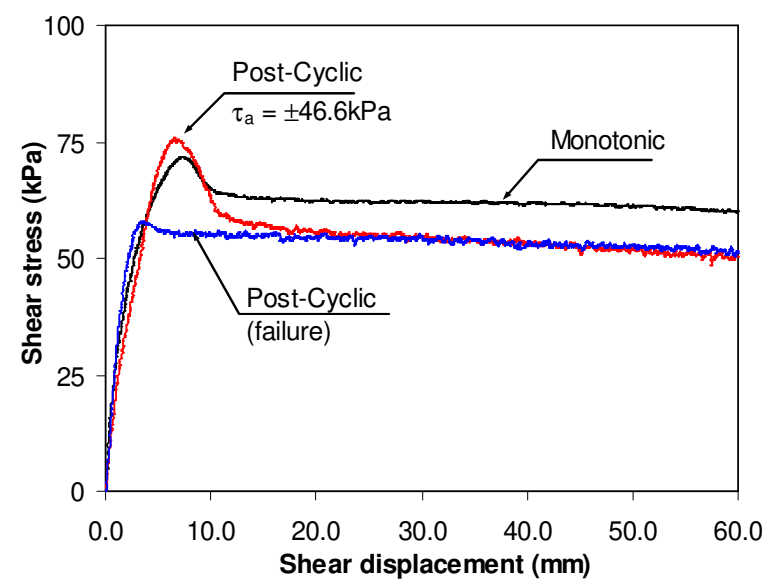

Figure 18. Effect of cyclic loading on the interface shear strength (load controlled tests, $\mathrm{f}=0.5 \mathrm{~Hz})$. 
This manuscript is the accepted version of the paper:

Sand-geotextile interface characterisation through monotonic and cyclic direct shear tests. Geosynthetics International, 20, No. 1, 26-38. DOI: 10.1680/gein.12.00037

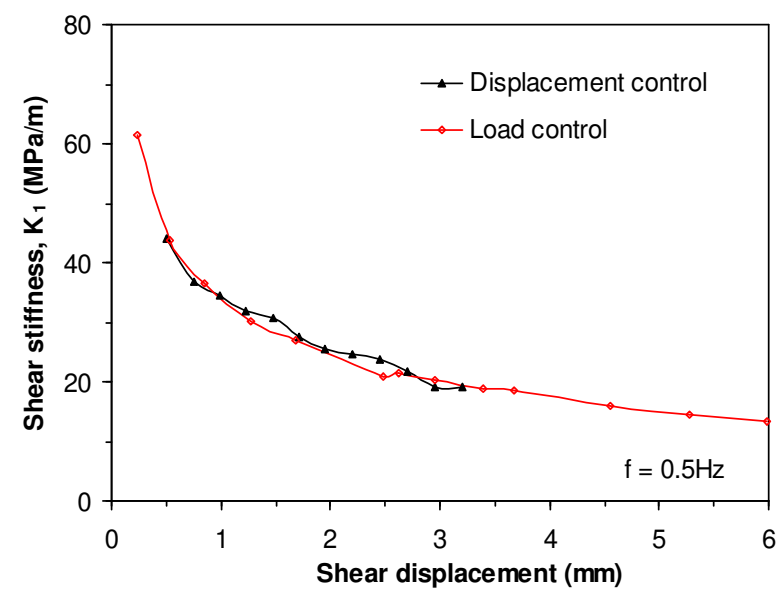

Figure 19. Comparison of the secant shear stiffness for the first cycle obtained by displacement and load controlled tests $(\mathrm{f}=0.5 \mathrm{~Hz})$. 
This manuscript is the accepted version of the paper:

Sand-geotextile interface characterisation through monotonic and cyclic direct shear tests. Geosynthetics International, 20, No. 1, 26-38. DOI: 10.1680/gein.12.00037

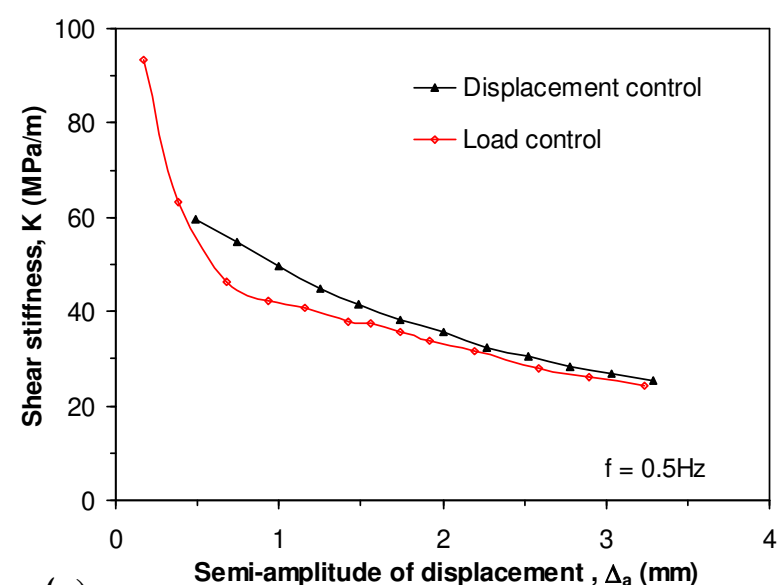

(a) Semi-amplitude of displacement, $\Delta_{\mathrm{a}}(\mathrm{mm})$

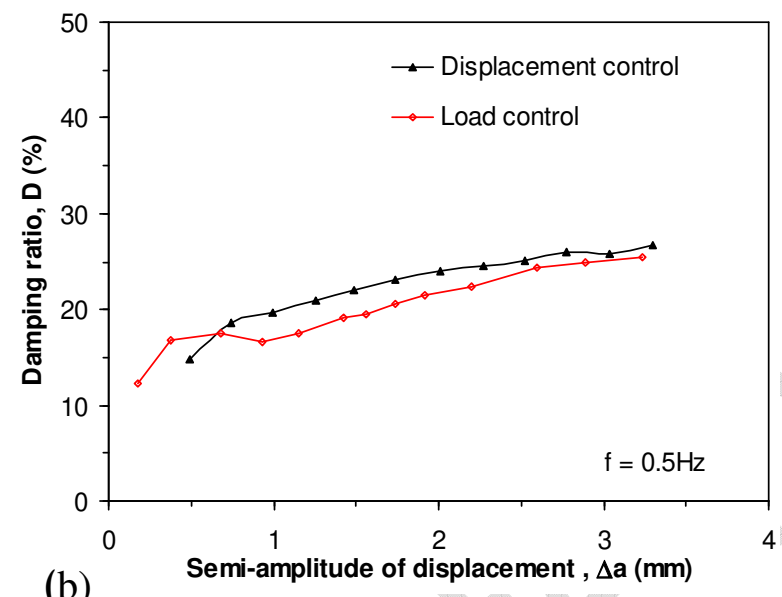

Figure 20. Comparison of results obtained by displacement and load controlled tests after 20 cycles $(f=0.5 \mathrm{~Hz})$ : a) interface shear stiffness; b) damping ratio. 
This manuscript is the accepted version of the paper:

Sand-geotextile interface characterisation through monotonic and cyclic direct shear tests. Geosynthetics International, 20, No. 1, 26-38. DOI: 10.1680/gein.12.00037

\section{LIST OF TABLES}

Table 1 . Summary of the reproducibility tests.

\begin{tabular}{|cccc|}
\hline Test & $\tau_{\mathbf{m a x}}(\mathbf{k P a})$ & $\Delta_{\mathbf{h x}}(\mathbf{m m})$ & $\tau_{\mathbf{4 0 \mathbf { m m }}}(\mathbf{k P a})$ \\
\hline Test 1 & 40.8 & 6.4 & 30.5 \\
Test 2 & 38.5 & 6.6 & 34.6 \\
Test 3 & 40.5 & 6.2 & 34.4 \\
Test 4 & 38.0 & 6.6 & 35.3 \\
Test 5 & 36.2 & 6.9 & 32.6 \\
\hline Mean & 38.8 & 6.6 & 33.5 \\
Standard deviation & 1.9 & 0.25 & 2.0 \\
Coef. of variation (\%) & 4.8 & 3.9 & 5.8 \\
\hline
\end{tabular}

